\title{
Novas espécies de Vidius Evans e Cobalopsis Godman \& Salvin do Brasil (Lepidoptera, Hesperiidae, Hesperiinae) 1
}

Olaf H. H. Mielke2

\begin{abstract}
The following new species are described: Vidius xanthus from São Paulo and Minas Gerais; Vidius catarinae from Santa Catarina; Cobalopsis monotona from Minas Gerais, São Paulo and Rio de Janeiro and Cobalopsis similis from Maranhão, Rondônia, Mato Grosso, Espírito Santo and Bahia.
\end{abstract}

Vidius xanthus sp. $\mathrm{n}$.

(Figs. 1-4 e 5)

Macho: Coloração geral de um castanho médio. Comprimento da asa anterior 14,5 a $15 \mathrm{~mm}$. Antena ventralmente esbranquiçada entre a base e a massa terminal e apículo internamente. Frontoclípeo ferrugíneo junto ao olho. Palpo esbranquiçado na base, passando a ferugíneo na parte distal e adjacente ao olho, terceiro artículo como a coloração geral. Gena ferrugínea. Tórax ventralmente esbranquiçado e com longas escamas ferrugíneas. Pernas ferrugíneas, algo esbranquiçadas internamente. Abdome ventralmente esbranquiçado, com vestígios de linha mediana escura e pleuras ferrugíneas.

Face dorsal da asa anterior com pequenas manchas discais brancas nos espaços $\mathrm{Cu}_{2}-2 \mathrm{~A}$ (opaca), $\mathrm{Cu}_{1}-\mathrm{Cu}_{2}$ e $\mathrm{M}_{3}-\mathrm{Cu}_{1}$ (semihialinas) e às vezes ainda uma pequena na metade superior da célula. Margem costal ferrugínea na base, margem interna com escamas esbranquiçadas na parte sub-basal até abaixo da mancha do espaço $\mathrm{Cu}_{2}-2 \mathrm{~A}$. Linha marginal pouco evidenciada e franjas pouco mais claras que a coloração geral.

Face dorsal da asa posterior com manchas discais alongadas, levemente amareladas e opacas nos espaços $\mathrm{M}_{3}-\mathrm{Cu}_{1}$ e $\mathrm{Cu}_{1}-\mathrm{Cu}_{2}$ e às vezes, em $\mathrm{Cu}_{2}-2 \mathrm{~A}$, muito difusa. Linha marginal e franjas como na mesma face da asa anterior.

Face ventral da asa anterior com toda a margem costal até à metade anterior da célula e veia $\mathrm{R}_{5}$ ferrugíneo; entre as veias $\mathrm{R}_{5}$ e $\mathrm{Cu}_{1}$ uma área triangular, com o vértice nas discocelulares, amarela; restante da asa anegrado e com as mesmas manchas discais da face dorsal. Linha marginal e franjas como na face dorsal da mesma asa.

1. Contribuição nº 658 do Departamento de Zoologia - UFPR. Com aux́lio do CNPq.

2. Departamento de Zoologia - UFPR. Caixa Postal 19020 - 81504 Curitiba - PR. Brasil. Bolsista do CNPq. 

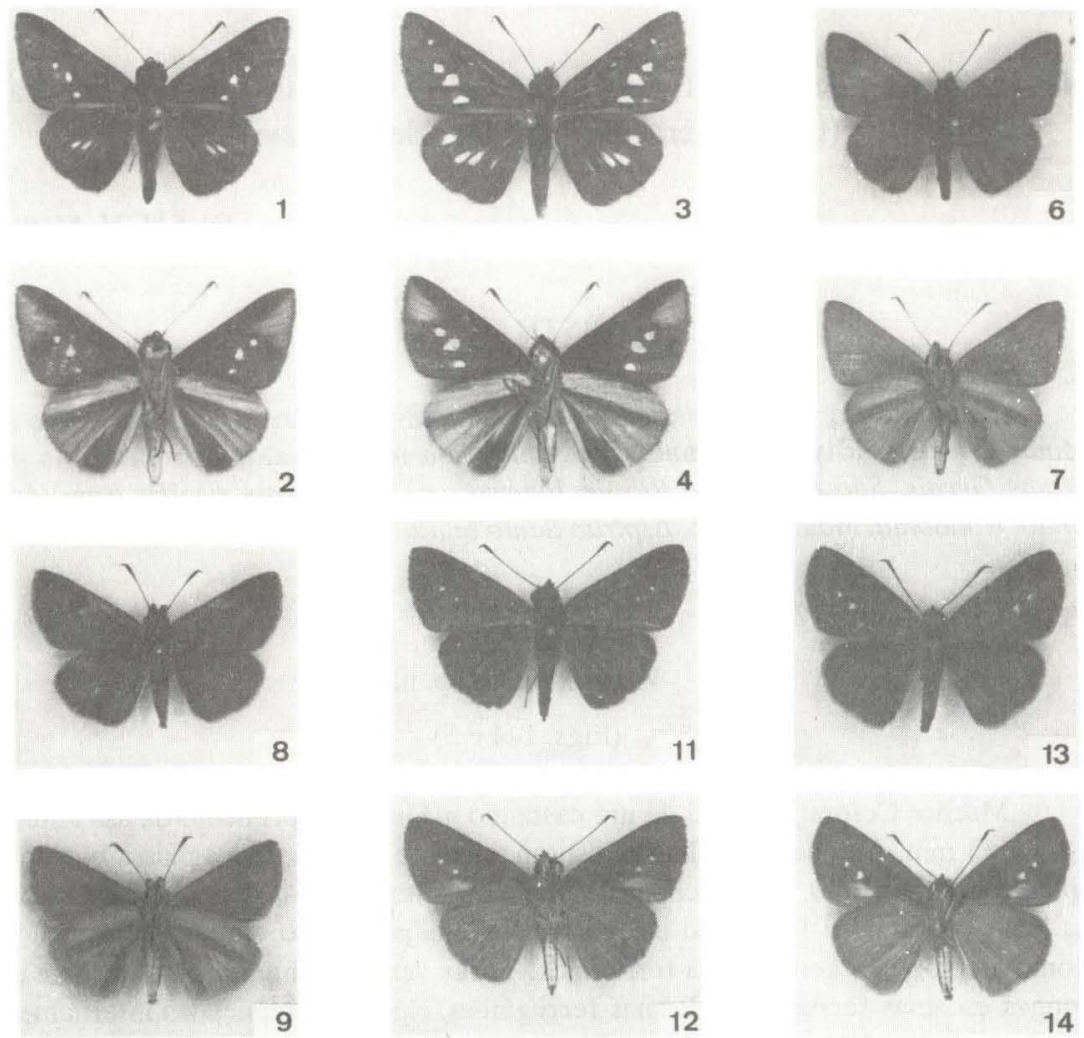

Figs. 1-4. Vidius xanthus sp. n. 1, holótipo macho, face dorsal e 2, face ventral; 3, alótipo fêmea, face dorsal e 4 , face ventral.

Figs. 6-9. Vidius catarinae sp. n. 6, holótipo macho, face dorsal e 7; face ventral, 8; alótipo fêmea, face dorsal e 9; face ventral.

Figs. 11-14. Cobalopsis miaba (Schaus). 11, macho, dorsal, 13-II-1965, Paineiras, Rio de Janeiro, Mielke leg., coleção do autor. 12, idem, face ventral; 13, fêmea, dorsal, 3-4-X-1987, Fenix, Paraná, 300 m, Mielke \& Casagrande leg., coleção do Departamento de Zoologia, Universidade Federal do Paraná. 14, idem, face ventral.

Face ventral da asa posterior com a margem costal ate $\mathrm{Sc}+\mathrm{R}_{1}$ e metade adjacente do espaço $\mathrm{Sc}+\mathrm{R}_{1}$-Rs ferrugíneas, posterior à esta coloração uma faixa amarelo-escura da base até a margem externa ocupando a metade superior da célula e atingindo a $\mathrm{M}_{1}$; depois seguindo uma área ferrugínea escura até $\mathrm{M}_{3}$ para, em segui$\mathrm{da}$, tornar-se ferrugíneo-clara até o meio anterior do espaço $\mathrm{Cu}_{2}-2 \mathrm{~A}$; metade posterior do espaço $\mathrm{Cu}_{2}-2 \mathrm{~A}$ e $2 \mathrm{~A}-3 \mathrm{~A}$ anegrados e margem interna amarelo-escura, com uma linha ferrugínea ao longo de $3 \mathrm{~A}$. Linha marginal não evidenciada e franjas ferrugíneas. 

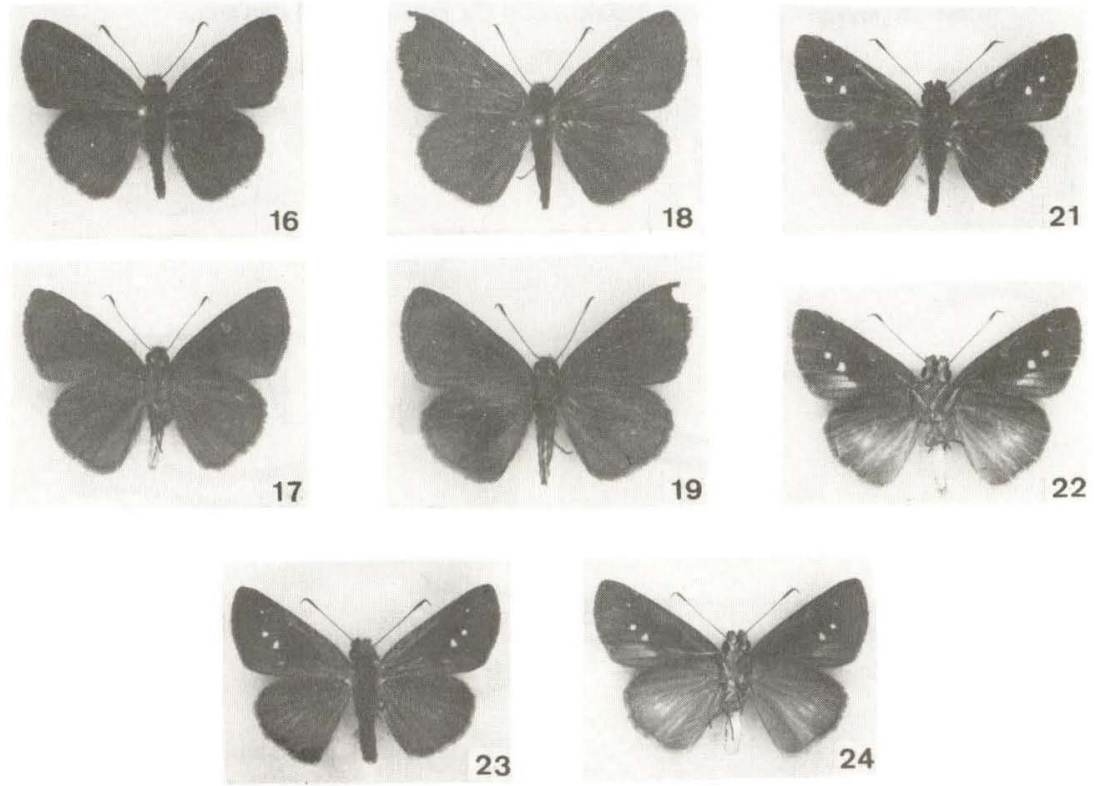

Figs. 16-19. Cobalopsis monotona sp. n. 16, holotipo macho, face dorsal e 17, face ventral; 18 , alotipo fêmea, face dorsal e 19, face ventral.

Figs. 21-24. Cobalopsis similis sp. n. 21, holótipo macho, face dorsal e 22, face ventral; 23, alótipo fêmea, face dorsal e 24 , face ventral.

Fêmea: Comprimento da asa anterior 15,5 a $16 \mathrm{~mm}$. Semelhante ao macho, porém com as asas mais arredondadas. A anterior sempre com pequena mancha, semelhante às discais, levemente amarelada, na metade superior da célula. Face dorsal da asa posterior com mais uma mancha discal entre Rs e $\mathrm{M}_{1}$ e todas um pouco maiores.

É a maior espécie do gênero e bastante característica pelo aspecto cromático da face ventral da asa posterior.

Todos os exemplares foram capturados dentro de brejos, com bastante gramíneas.

Holótipo macho e alótipo fêmea, 8-12-II-1982, Campos do Jordão, São Paulo, 1600-2000 m, Mielke \& Casagrande leg., n DZ 3.444 e 3.445, respectivamente, coleção do Departamento de Zoologia, Universidade Federal do Paraná. Parátipos: 3 machos e 2 fêmeas com os mesmos dados do holótipo, no DZ 3.298, $3.350,3.446,3.299$ e 3.447, na mesma coleção. 1 macho, 31.III.1965, Morro do Ferro, Poços de Caldas, Minas Gerais, 1600 m, Mielke leg., nº 6.792, coleção do autor, depositada na coleção do Departamento de Zoologia, Universidade Federal do Paraná. 
O nome específico é alusivo à coloração da face ventral das asas.

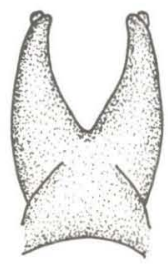

a

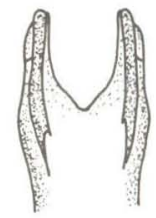

b

$1 \mathrm{~mm}$

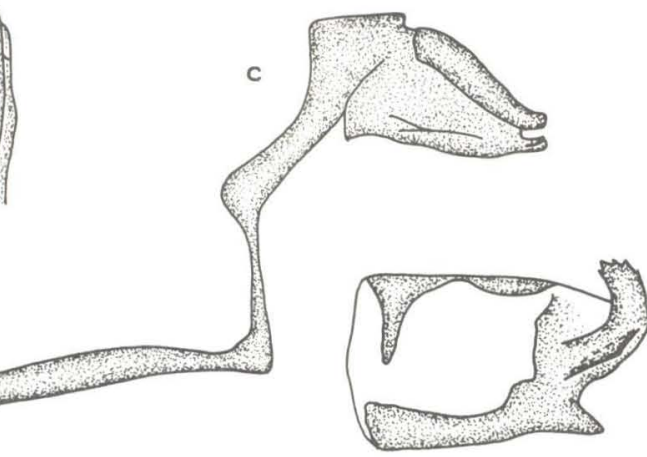

d

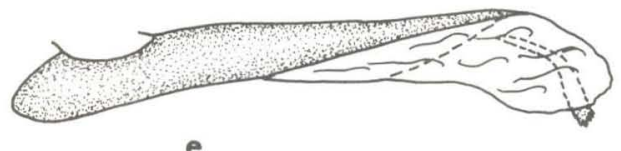

e

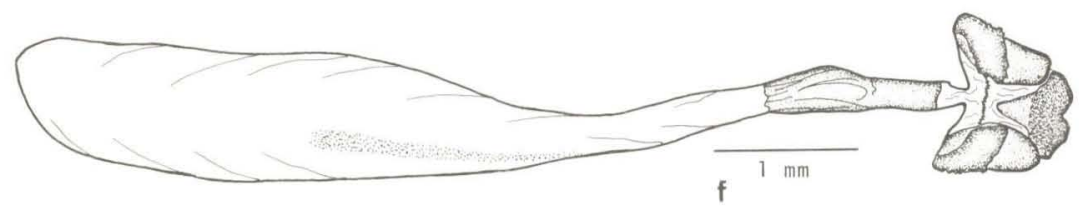

Fig. 5. Vidius xanthus sp. n. Genitália masculina (DZ 3.350). a, vista dorsal do unco e gnato; $b$, vista ventral do gnato e unco; c, vista lateral esquerda do tegumen, saco, unco e gnato; d, vista interna da valva direita; e, vista lateral esquerda do edéago; $f$, Genitália feminina (DZ 3.299), vista ventral do esterigma e bolsa copuladora.

Vidius catarinae sp. $\mathrm{n}$.

(Figs. 6-9 e 10)

Macho: Coloração geral de um castanho médio. Comprimento da asa anterior 12 a $12,5 \mathrm{~mm}$. Antena ventralmente esbranquiçada na base de cada artículo, entre a base e o meio da haste e dai até o apículo, todo o artículo, e internamente no apículo. Frontoclípeo, vértice, colar, patágias e tégulas com escamas isoladas ocráceas. Palpo esbranquiçado na base, passando a ocráceo na parte distal, onde há mescla com escamas da coloração geral, e ocre junto ao olho; terceiro artículo da coloração geral. Gena ocrácea. Tórax ventralmente com longas escamas esbranquiçadas. Pernas 


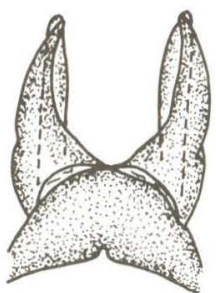

a

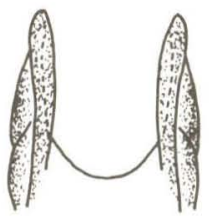

b



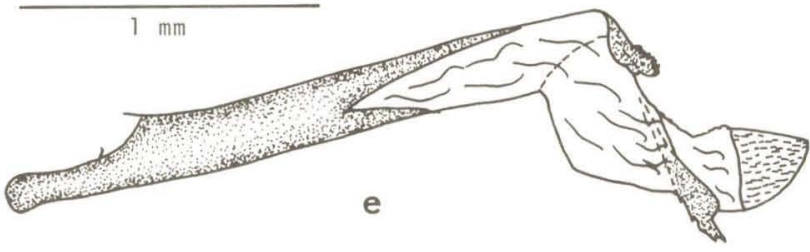

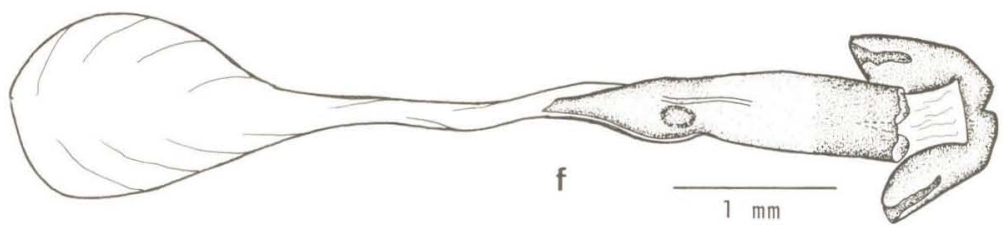

Fig. 10. Vidius catarinae sp. n. Genitália masculina (DZ 3.484). a, Vista dorsal do unco e gnato; b, vista ventral do gnato e unco; $c$, vista lateral esquerda do tegumen, saco, unco e gnato; $d$, vista interna da valva direita; e, vista lateral esquerda do edéago; $f$, Genitália feminina (DZ 3.442), vista ventral do esterigma e bolsa copuladora.

ocráceas. Abdome ventralmente esbranquiçado e com indícios de linha mediana escura.

Face dorsal das asas anterior e posterior sem qualquer desenho; a anterior com scamas esparsas ocráceas. Linha marginal pouco evidenciada e franjas concolores.

Face ventral da asa anterior com a margem costal, o ápice e a margem externa, do ápice até $\mathrm{Cu}_{2}$, ocre; restante castanho escuro. Linha marginal não evidenciada e frajas ocre-claras.

Face ventral da asa posterior ocre-clara, um pouco mais escura na margem costal e metade externa entre $\mathrm{Sc}+\mathrm{R}_{1}-\mathrm{Rs}$; uma faixa castanho-escura da base até a margem externa através da célula e os espaços $\mathrm{M}_{1}-\mathrm{M}_{2}$ e $\mathrm{M}_{2}-\mathrm{M}_{3}$; espaço 2A-3A castanho-anegrado. Linha marginal não evidenciada e franjas ocre-claras.

Fêmea: Comprimento da asa anterior 12,5 a $13 \mathrm{~mm}$. Semelhante ao macho, porém com as asas mais arredondadas. 
É uma espécie bastante característica pelo aspecto cromático da face ventral da asa posterior.

Holotipo macho e alótipo fêmea, 26-II-1973, Mantiqueira, São Joaquim, Santa Catarina, 1400 m, Mielke leg., nº DZ 3.448 e 3.449, respectivamente, coleção do Departamento de Zoologia, Universidade Federal do Paraná. Parátipos: 3 fêmeas com os mesmos dados do holótipo, no DZ 3.450 a 3.452. 3 machos e 4 fêmeas, 25II-1973, Urubici, Santa Catarina, 1500 m, Mielke leg., no DZ 3.434, 3.453, 3.454, 3.442 , 3.355 e 3.457. 1 macho e 1 fêmea, 1-12-II-1973, São Joaquim, Santa Catarina, Ebert leg., ex col. H. Ebert, n DZ 3.458 e 3.459. Todos na mesma coleção do holótipo.

O nome é alusivo ao estado onde foram coletados os exemplares.

\section{Cobalopsis miaba (Schaus, 1902)}

(Figs. 11-14 e 15)

Megistias miaba Schaus, 1902: 450, sem indicação de sexo e localidade, tipo no 6.043, USNM.

Euroto potaro Williams \& Bell, 1931: 277, fig. 29 (genitália masculina) e pl. 25, fig. 10 (macho, dorsal e ventral), tipo macho, 28-VI-1927, Tumatumari, Potaro River, British Guiana, Ac. Nat. Sc. Philadelphia.

Papias elegans Hayward, 1940; 875, fig. 17 (genitália masculina), holótipo macho, Macas, Rio Upano, Equador, $1000 \mathrm{~m}$, Amer. Mus. Nat. Hist.

Cymaenes miaba; Evans, 1955: 137.

Cobalopsis potaro; Evans, 1955: 160, pl. 64 (genitália masculina), syn.: elegans.

Cobalopsis miaba; Mielke, 1980: 145, syn.: potaro.

Examinando os hol6tipos de M. miaba, E. potaro (agora no Carnegia Museum para onde foram transferidos quase todos os tipos da Ac. Nat. Sc. Philadelphia) e $P$. elegans, chegou-se à conclusão serem sinônimos. A espécie é muito variável, porém a genitália é constante.

Para caracterizar a espécie, principalmente porque duas espécies próximas são descritas a seguir, apresenta-se aqui figuras do macho, da fêmea e suas respectivas genitálias.

\section{Cobalopsis monotona sp. n.}

(Figs. 16-19 e 20)

Macho: Coloração geral de um castanho médio, algo acinzentado. Comprimento da asa anterior: 14 a $15 \mathrm{~mm}$. Antena ventralmente esbranquiçada na base de cada artículo e metade basal da massa terminal, e internamente no apículo. Frontoclípeo com tufo de escamas esbranquiçadas junto ao olho e escamas esparsas desta coloração no vértice. Palpo com mescla de escamas esbranquiçadas e escuras, estas ausentes junto ao olho, formando uma área esbranquiçada. Gena esbranquiçada. Tórax e abdome ventralmente e pernas internamente esbranquiçadas, o abdome com linha mediana escura. 
Vol. 6(4), 1989

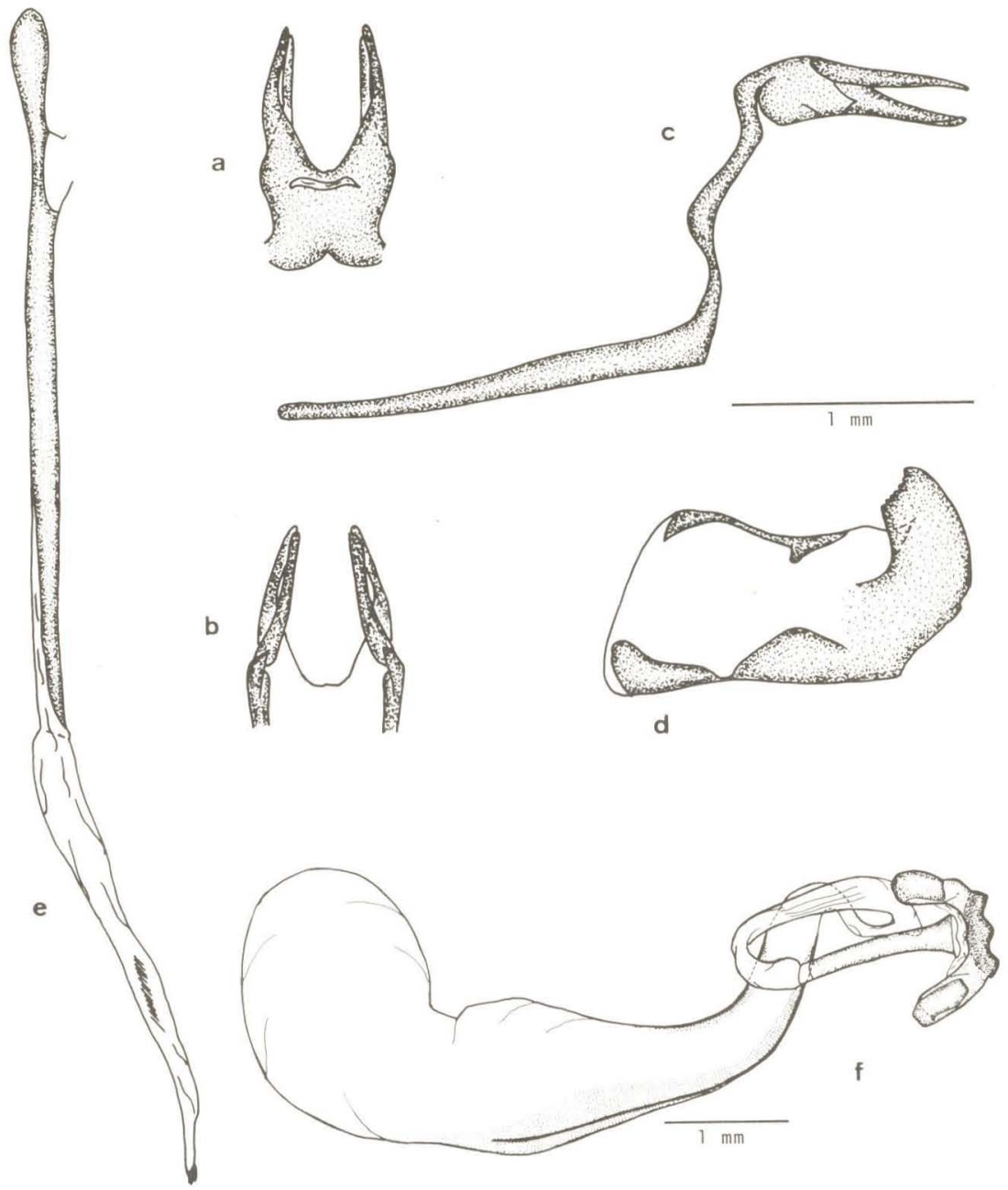

Fig. 15. Cobalopsis miaba (Schaus). Genitália masculina (21-II-1966, Jardim Zoológico, Brasília, Distrito Federal, Mielke leg., no OM 9.071). a, vista dorsal do unco e gnato; b, vista ventral do gnato e unco; c, vista lateral esquerda do tegumen, saco, unco e gnato; $d$, vista interna da valva direita; e, vista lateral esquerda do edéago; $f$, Genitália feminina (21-II-1966, Jardim Zoológico, Brasília, distrito Federal, Mielke leg., no OM 9.084), vista ventral do esterigma e bolsa copuladora.

Face dorsal das asas anterior e posterior uniformemente da coloração geral. Linha marginal não evidenciada e franjas concolores.

Face ventral da asa anterior com as áreas costal e apical da coloração geral; o restante anegrado. Linha marginal anegrada bem destacada, com exceção no torno. Franjas concolores. 

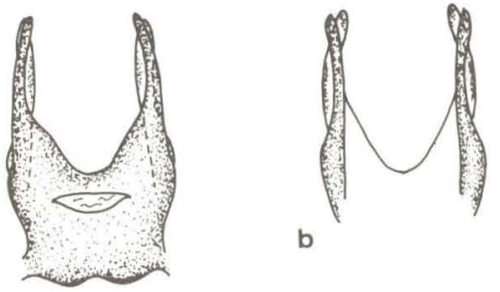

b

a
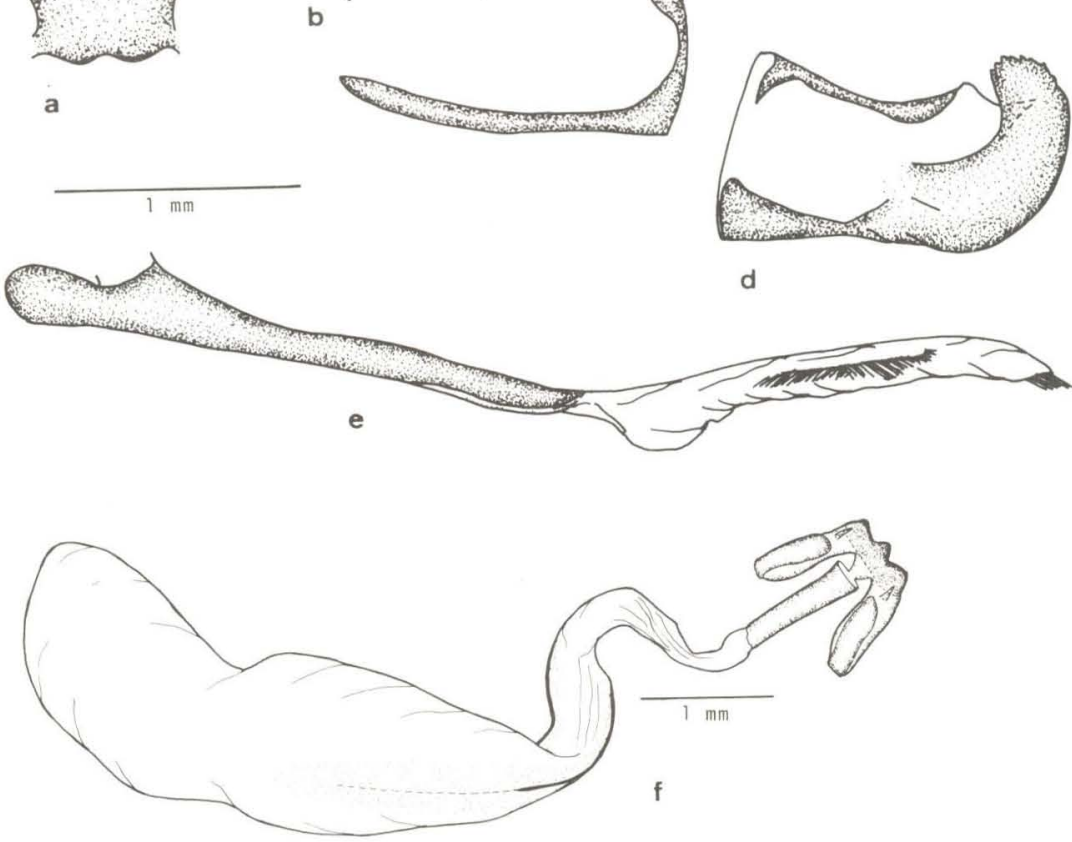

Fig. 20. Cobalopsis monotona sp. n. Genitália masculina (DZ 3.258). a, vista dorsal do unco e gnato; $b$, vista ventral do gnato e unco; $c$, vista lateral esquerda do tegumen, saco, unco e gnato; d, vista interna da valva direita; e, vista lateral esquerda do edéago; $f$, Genitália feminina (DZ 3.289), vista ventral do esterigma e bolsa copuladora.

Face ventral da asa posterior, com exceção da parte posterior do espaço $\mathrm{Cu}_{2}-$ $2 \mathrm{~A}$ e todo o espaço $2 \mathrm{~A}-3 \mathrm{~A}$ anegrados, como as áreas costal e apical da mesma face da asa anterior; cinco manchas discais pouco nítidas e constituidas de poucas escamas nos espaços entre $\mathrm{Rs}$ e $\mathrm{Cu}_{2}$. Linha marginal anegrada e franjas concolores.

Fêmea: Comprimento da asa anterior: 14 a $16 \mathrm{~mm}$. Semelhante ao macho, diferindo somente pelas asas um pouco mais arredondadas.

Espécie muito próxima de $C$. miaba (veja linhas atrás), da qual se distingue externamente pelas manchas discais da face ventral da asa posterior muito apagadas, pela ausência da mancha clara difusa no espaço $\mathrm{Cu}_{2}-2 \mathrm{~A}$ na face ventral da asa anterior, pela ausência total de manchas discais brancas da asa anterior nos dois sexos, pela valva sem protuberância na margem inferior, pela terminação da valva paralela 
à sua costa, pelos cornutos basais que ocupam um terço do comprimento do edéago, pela presença de dois espinhos medianos no esterigma e pela abertura circular do бstio, enquanto que em C. miaba as manchas discais da face ventral da asa posterior são nítidas, o espaço $\mathrm{Cu}_{2}-2 \mathrm{~A}$ da face ventral da asa anterior sempre tem uma mancha difusa clara, as fêmeas sempre e os machos ocasionalmente possuem manchas discais e às vezes também algumas apicais brancas, a valva possui uma protuberância na margem inferior, a terminação da valva é obliqua à sua costa, os cornutos basais ocupam aproximadamente um oitavo do comprimento do edéago, o esterigma não possui espinhos e a abertura do óstio é oval.

Holotipo macho e alótipo fêmea, 1-5-II-1985, Caraça, Santa Bárbara, Minas Gerais, $1300-1500$ m, Mielke \& Casagrande leg., $n^{\circ}$ DZ 3.338 e 3.339, respectivamente, Departamento de Zoologia, Universidade Federal do Paraná. Parátipos: 8 machos com os mesmos dados do holótipo, $\mathrm{n}^{\circ}$ DZ 3.288 e 3.340 a 3.346; 2 machos 2-XI-1966, 1 macho 12-XII-1966, 1 macho 11-II-1967, 1 macho 28-V-1967, Poços de Caldas, Minas Gerais, 1250 m, Ebert leg., $\mathrm{n}^{\circ} 3.333,3.331,3.332,3.336$ e 3.330; 1 macho e 1 fêmea 21-I-1952, Barbacena, Minas Gerais, 1100 m, Ebert leg., n̊ 3.347 e 3.334; 1 macho e 2 fêmeas 15-II-1984, Barreira de Piquete, Piquete, São Paulo, 1400-1600 m, Mielke \& Casagrande leg., $\mathrm{n}^{\circ}$ 3.348, 3.349 e 3.289; 1 macho 26-II-1967, Teresópolis, Rio de Janeiro, 1500 m, Ebert leg., nº DZ 3.335; coleção do Departamento de Zoologia, Universidade Federal do Paraná. 2 fêmeas 27III-1965, 1 macho 28-III-1965, 7 machos e 6 fêmeas 29-III-1965, 1 macho 30III-1965, 1 fêmea 31-III-1965, 1 macho 1-IV-1965, 3 machos 2-VI-1965, 1 fêmea 4-IV-1965, Morro do Ferro, Poços de Caldas, Minas Gerais, $1600 \mathrm{~m}$, Mielke

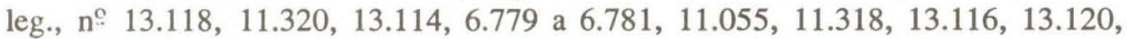
$6.782,6.783,13.119,13.121$ a $13.123,13.117,13.113,13.111,13.112,13.126$, 13.127 e 11.319; 1 macho 1-XII-1988, Caraça, Santa Bárbara, Minas Gerais, 1300 m, O. \& E. J. Mielke leg., $\mathrm{n}^{\mathrm{Q}}$ 19.359; 2 machos e 2 fêmeas 3-XII-1988, Monteverde, Camanducaia, Minas Gerais, 1500-1800 m, O. \& E. J. Mielke leg., no 19.464, $19.465,19.462$ e 19.463; 1 macho 28-IV-1962, 1 macho 30-IV-1926, PNSO, Teresópolis, Rio de Janeiro, 1400-1500 m, Mielke leg., nº 4.419 e 4.425 e 1 fêmea 25 II-1966, Petrópolis, Rio de Janeiro, 1100 m, Mielke leg., n 11.628; coleção do autor, depositada na coleção do Departamento de Zoologia, Universidade Federal do Paraná.

O nome é alusivo à monotonia de sua coloração.

\section{Cobalopsis similis $\mathbf{s p .} \mathbf{n}$.}

(Figs. 21-24 e 25)

Macho: Coloração geral de um castanho médio. Comprimento da asa anterior: 14 a $16 \mathrm{~mm}$. Antena ventralmente esbranquiçada na base de cada artículo, na metade basal da massa terminal, esparsamente na metade distal da massa terminal e internamente no apículo. Frontoclípeo com tufo de escamas esbranquiçadas junto ao olho e com poucas escamas desta coloração. Palpo com mescla de escamas esbran- 


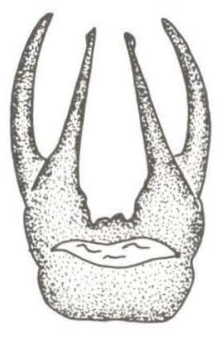

a
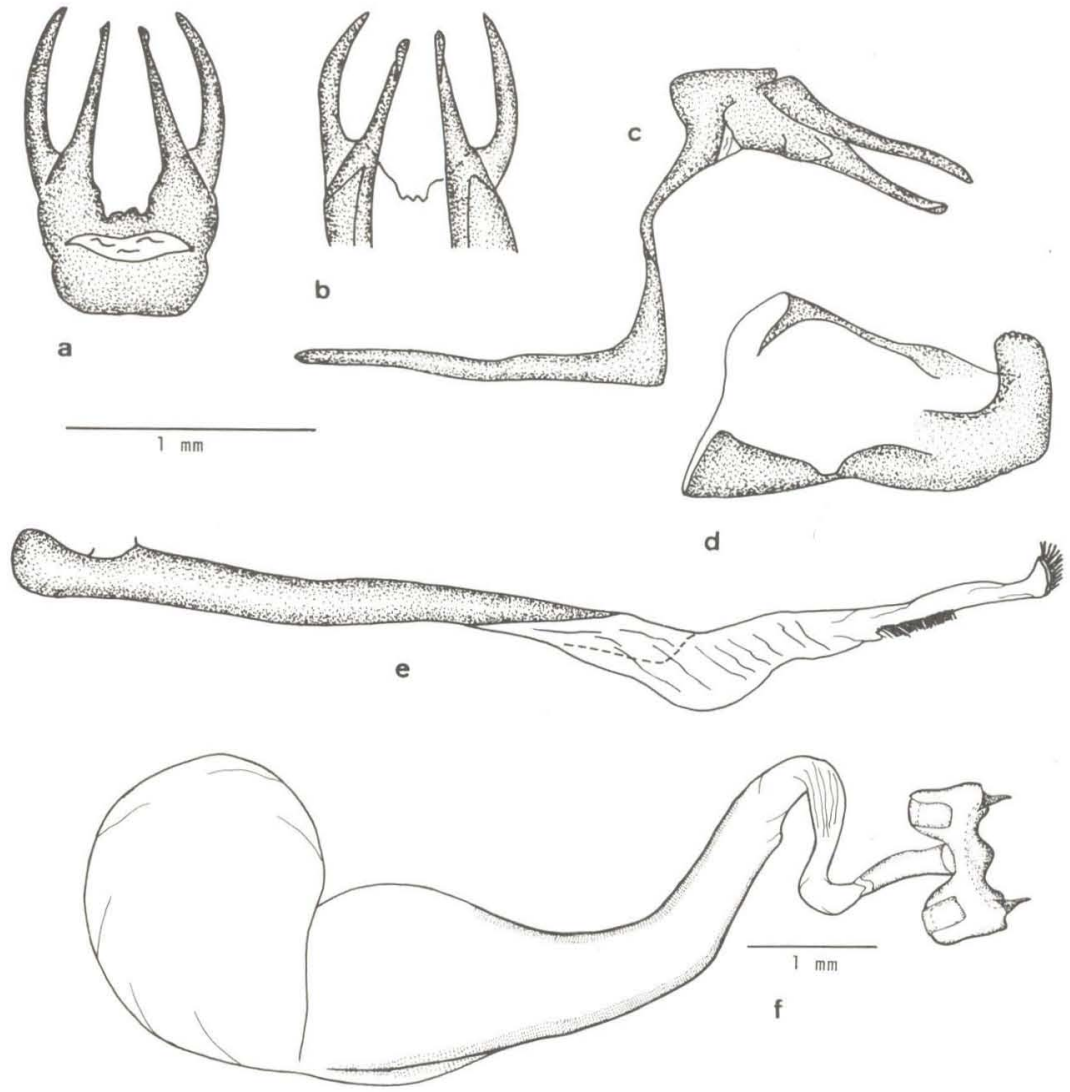

Fig. 25. Cobalopsis similis sp. n. Genitália masculina (DZ 3.300). a, vista dorsal do unco e gnato; b, vista ventral do gnato e unco; $c$, vista lateral do tegumen, saco, unco e gnato; d, vista interna da valva direita; e, vista lateral esquerda do edéago; $f$, Genitália feminina (DZ 3.301), vista ventral do esterigma e bolsa copuladora.

quiçadas e escuras. Gena esbranquiçada. Tórax ventralmente e pernas internamente esbranquiçadas e abdome ventralmente branco sem linha mediana escura.

Face dorsal da asa anterior uniforme e com manchas discais irregulares nos espaços $\mathrm{Cu}_{1}-\mathrm{Cu}_{2}, \mathrm{M}_{3}-\mathrm{Cu}_{1}$ e apicais diminutas nos espaços $\mathrm{R}_{5}-\mathrm{M}_{1}$ e $\mathrm{R}_{4}-\mathrm{R}_{5}$ (este geralmente ausente). Linha marginal não destacada $\mathrm{e}$ franjas concolores.

Face dorsal da asa posterior uniforme ou com indicação das manchas discais da face ventral. Linha marginal como na mesma face da asa anterior e franjas um pouco acinzentadas, principalmente no ângulo anal.

Face ventral da asa anterior com as áreas costal e apical da coloração geral, área basal anegrada e torno cinza-escuro; espaço $\mathrm{Cu}_{2}-2 \mathrm{~A}$ com mancha esbranqui- 
çada difusa, grande ou dividida em duas superpostas, e as mesmas manchas discais e apicais brancas da face dorsal. Linha marginal castanho-escura e franjas concolores.

Face ventral da asa posterior com a margem costal de coloração geral passando a castanho-acinzentada nas áreas basal e marginal externa e espaço 2A-3A; áreas discal e marginal interna cinza-esbranquiçadas difusas, às vezes chegando até à margem externa através da metade superior do espaço $\mathrm{Cu}_{2}-2 \mathrm{~A}$; cinco manchas discais difusas e esbranquiçadas, de tamanhos crescentes, entre os espaços $\mathrm{M}_{1}$ e $2 \mathrm{~A}$. Linha marginal castanho-escura e franjas concolores.

Fêmea: Mesmo tamanho e muito semelhante ao macho, porém a área discal cinza-esbranquiçada da face ventral da asa posterior geralmente mais abrangente, sendo que num exemplar de Açailândia, Imperatriz, Maranhão, ocupa quase toda a asa, deixando somente a área costal de coloração geral; as manchas apicais geralmente atingem o espaço $\mathrm{R}_{3}-\mathrm{R}_{4}$.

Espécie muito próxima da $C$. miaba (veja linhas atrás), da qual se destingue imediatamente pela área esbranquiçada da face ventral da asa posterior, além da presença constante de manchas discais na asa anterior. Na genitália masculina, a ponta da valva recurvada dorsalmente termina de modo paralelo à costa em $C$. similis e de modo oblíquo em $C$. miaba; esta ainda possui uma pequena projeção na margem inferior da valva, não desenhada nas figuras de WILLIAMS \& BELL (1931) e EVANS (1955). Na genitália feminina, C. miaba não possui os dois espinhos na parte distal do esterigma.

Holotipo macho, 9-VII-1974 e alótipo fêmea, 17-VIII-1974, Imperatriz, Maranhão, Mielke, Lauterjung, Cano \& Souza leg., no DZ. 3.302 e 3.303, respectivamente, na coleção do Departamento de Zoologia, Universidade Federal do Paraná. Parátipos: 1 fêmea 3-VII-1974, 1 macho 4-VII-1974, 2 machos 5-VII-1974, 1 macho 15-VII-1974, 1 fêmea 20-VII-1974, 1 macho 24-VII-1974, 1 macho 9VIII-1974 e 1 fêmea 24-VIII-1974, mesmos dados do holótipo, n DZ 3.304 a 3.312; 1 macho 15-VIII-1974, 1 fêmea 20-VIII-1974, 3 machos e 2 fêmeas 22VIII-1974, 2 machos e 2 fêmeas 23-VIII-1974 e 1 macho 26-VIII-1974, Açailândia, Imperatriz, Maranhão, nº DZ 3.314, 3.315, 3.300, 3.316 a 3.322, 3.301 e 3.323; 1 fêmea 7-VII-1972 e 1 macho 9-VII-1972, Riozinho, Pimenta Bueno, Rondônia, 200 m, Mielke \& Brown leg., no DZ 3.324 e 3.293; 1 macho 14-VII-1972, 31 km NO de Barra do Bugres, Mato Grosso, 200 m, Mielke \& Brown leg., n DZ 3.295; 1 macho 17-22-IX-1973, 1 macho e 1 fêmea 10-15-IV-1974, 1 macho e 2 fêmeas 19-24-VI-1974, 1 fêmea 17-22-VI-1974, 1 macho 4-VII-1974, Linhares, Espírito Santo, Elias leg., no DZ 3.294, 3.325 a 3.329, 3.297 e 3.296; mesma coleção do holótipo. 1 macho e 1 fêmea X-1920, Rio Guandu, Espírito Santo, n 12.797 e 12.801; 1 fêmea 20-XII-1966, Ubatã, Bahia, Brown leg., no 20.445; 1 fêmea 19-VI-1978, Ouro Preto, Rondônia, Raw leg., nº 20.444; 1 fêmea 19-I-1978, Fazenda São João, Alto Rio Arinos, Diamantino, Mato Grosso, Mielke \& Furtado leg., no 20.441; coleção do autor, depositada no Departamento de Zoologia, Universidade Federal do Paraná.

O nome específico ê alusivo à semelhança desta espécie com Cobalopsis miaba. 


\section{AGRADECIMENTOS}

Agradeço aos Drs. John Burns e Robert Robbins (National Museum of Natural History, Smithsonian Institution, Washington), Chen Young e Bob Davidson (Carnegie Museum, Pittsburgh), Frederick Rindge e James Miller (American Museum of Natural History, N. York) e R. I. Vane-Wright e P. Ackery (British Museum of Natural History, Londres) por permitirem estudar tipos sob suas responsabilidades e Pe. Jesus S. Moure pela revisão do manuscrito.

\section{REFERÊNCIAS}

EVANS, W. H., 1955. A catalogue of the american Hesperiidae Part IV. Hesperiinae and Megathyminae. pp. V+499, pls. 54-88. British Museum (Nat. Hist.), Londres, Inglaterra.

HAYWARD, K. J., 1940. New species of neotropical Hesperiidae from Ecuador (Lep.). Revta. Ent., Rio de Janeiro, 11(3): 861-877.

MIELKE, O. H. H., 1980. Contribuição ao estudo faunístico dos Hesperiidae americanos. VI Nota suplementar às espécies de Hesperiinae do Rio Grande do Sul, Brasil (Lepidoptera). Acta Biol. Paranaense, Curitiba, 8-9: 127-172, 77 figs.

SCHAUS, W. 1902. Descriptions of new american butterflies. Proc. U. S. Nat. Mus., 24: 383-460.

WILLIAMS JR. R. C. \& E. L. BELL, 1931. Hesperiidae of the Forbes Expedition to Dutch and British Guiana (Lepidoptera). Trans. Amer. ent. Soc., 57: 249-290, 34 figs. 